\title{
Negation and polarity: an introduction
}

\author{
Doris Penka $\cdot$ Hedde Zeijlstra
}

Accepted: 9 September 2010 / Published online: 26 November 2010

(C) The Author(s) 2010. This article is published with open access at Springerlink.com

\begin{abstract}
This introduction addresses some key issues and questions in the study of negation and polarity. Focussing on negative polarity and negative indefinites, it summarizes research trends and results. Special attention is paid to the issues of synchronic variation and diachronic change in the realm of negative polarity items, which figure prominently in the articles and commentaries contained in this special issue.
\end{abstract}

Keywords Negative polarity $\cdot$ Negative indefinites $\cdot$ n-words $\cdot$ Negative concord Synchronic variation - Diachronic change

\section{Background}

This special issue takes its origin in the workshop on negation and polarity (NegPol07) that was held at the University of Tübingen in March 2007. The workshop was hosted by the Collaborative Research Centre 441 "Linguistic Data Structures" and funded by the German Research Council (DFG). Its aim was to bring together researchers working on theoretical aspects of negation and polarity items as well as the empirical basis surrounding these phenomena.

One of the reasons to organize this workshop, and to put together this special issue, is that after several decades of generative research it is now generally felt that quite some progress has been made in understanding the general mechanics and motivations behind negation and polarity items. At the same time, it becomes more and

D. Penka (西)

Zukunftskolleg and Department of Linguistics, University of Konstanz, Box 216, 78457 Konstanz, Germany

e-mail: doris.penka@uni-konstanz.de

H. Zeijlstra (凶)

University of Amsterdam, Spuistraat 134 (cg NTK), 1012 VB Amsterdam, The Netherlands

e-mail: zeijlstra@uva.nl 
more evident that the more subtle cross-linguistic variation in especially the domain of negative polarity requires further study and explanation. One of the central goals of this issue is to provide a series of articles that focus on more unexpected occurrences of or restrictions on the licensing of negative polarity items. Moreover, the insight is starting to emerge that for a full understanding of negation and polarity, diachronic development has to be taken into account. Accordingly, several of the articles in this volume investigate the topic from a diachronic perspective.

Four of the papers now contained in this issue were presented at the workshopthe ones by Condoravdi, Hoeksema, Jäger and Soehn et al. The first three feature as topic articles and are accompanied by a commentary. This topic-comment format enhances the discussion of one issue from different, sometimes complementary, perspectives. This, we hope, will provide a balanced discussion and make this volume also representative for what is currently going on in the study of negation and polarity phenomena.

In the remainder of this introduction, we will try and give an overview of the most central questions and insights of research on the syntax and semantics of negative polarity and negative indefinites. This, we hope, will also lay the basis for reading the following research articles, which primarily discuss these topics. Needless to say, we cannot do justice to the vast literature on negation and polarity and can only give a glimpse of research on the topic. For an overview of other issues in the study of negation and polarity, the reader is referred to Horn (1989); Ladusaw (1996); Zanuttini (2001); Zeijlstra (2004, 2007, 2010); and Giannakidou (2010a).

\section{Negative Polarity Items}

Negative Polarity Items (NPIs) are words or expressions that can only occur in contexts that are in some sense negative. The prime examples are DPs that involve any in English, whose sensitivity to negation is evidenced by the contrast in (1), but many other examples, both in English and other languages, have been attested too.

$$
\begin{aligned}
& \text { a. } \quad \text { *I saw anybody. } \\
& \text { b. I didn't see anybody. }
\end{aligned}
$$

However, it is not just sentential negation that is responsible for the wellformedness of sentences containing NPIs. NPIs are known to occur in other types of contexts as well, such as first argument positions of universal quantifiers, interrogatives, and the scope of items such as at most DPs or semi-negative expressions like hardly as in $(2){ }^{1}$

(2) a. Every student who owns any BMW is tasteless.

b. John hardly likes any cookies.

c. At most three students did any homework.

Already on the basis of these examples, two important questions suggest themselves: (i) what are the properties of contexts in which NPIs are allowed; and (ii)

${ }^{1}$ Examples taken from Zeijlstra (2010). 
what properties do NPIs like anything have, such that they may only appear in negative (or semi-negative) contexts? It is primarily these two questions that have guided the study of negative polarity over the past thirty years and we will address them in turn in the remainder of this section.

\subsection{NPI licensing contexts}

According to a very influential approach, going back to Fauconnier $(1975,1979)$ and Ladusaw (1980), NPIs are licensed in contexts that are scale-reversing or downward entailing. In other words, NPI licensing contexts allow inferences from more general to more specific properties. ${ }^{2}$ This does not only hold for negation, but also for the contexts in (2). For instance, the inference in (3) is valid, which shows that the scope of DPs formed with at most constitutes a downward entailing context. Consequently, any can occur under at most DPs, as shown in (2c).

At most three people ordered meat. $\rightarrow$ At most three people ordered a steak.

While the assumption that NPIs are licensed in downward entailing contexts has been very successful, it requires a number of refinements. The first refinement, or challenge, concerns the fact that the class of NPI licensing contexts appears to be richer than the class of all downward entailing contexts. For instance, environments created by only can license NPIs as well, as is shown in (4).

(4) Only John had anything to eat.

However, the inference in (5) does not seem to be intuitively valid.

Only John had dessert. $\nrightarrow$ Only John had ice cream.

The problem is that the consequent in (5) implies that John had ice cream, while there is no such implication coming from the antecedent. As this implication has been argued to have the status of a presupposition associated with only (a.o. Horn 1969), it seems that presuppositions are disregarded in computing entailment relations for the licensing of NPIs. More precisely, the validity of entailment inferences has to be judged in situations in which the presuppositions of the conclusion are fulfilled. von Fintel (1999) proposes that this notion of downward entailment where the presuppositions of the consequent are taken to be true, called 'Strawson downward entailment', 3 is the one relevant for NPI licensing. This accounts for the licensing of NPIs in the scope of only. If (5) is judged against a background in which it is taken for granted that John had ice cream, the inference is indeed valid.

\subsection{Variation in the domain of NPI licensing}

While the notion of (Strawson) downward entailment has been proposed on the basis of English NPIs, it is not sufficient to account for the licensing of NPIs cross-

\footnotetext{
${ }^{2}$ Formally, a function $f$ is downward entailing iff for all $X, Y$ in the domain of $f: X \subseteq Y \rightarrow f(Y) \subseteq f(X)$.

${ }^{3}$ The name refers to Strawson's (1952) proposal that in order to assess validity of entailments in traditional logic, it has to be assumed that the involved statements are either true or false, i.e., their semantic presuppositions are fulfilled.
} 
linguistically. There are NPIs in some languages that can occur in a wider set of environments than downward entailing ones. In Greek for instance, NPIs can also occur in imperatives and certain modal contexts, as illustrated in (6).
a. Pijene se kanenan jatro!
Go.IMP.2SG to any doctor
'Go to a doctor!'
b. Prepi na episkeftis kanenan jatro.
Must.2SG SUBJ visit any doctor
'You must visit a doctor.'

Giannakidou (1997, 1999) proposes that NPIs in Greek are sensitive to an even weaker form of negativity: non-veridicality. ${ }^{4}$ A propositional operator $F$ is nonveridical if $F(p)$ does not entail or presuppose that $p$ is true in some individual's epistemic model.

Another complicating factor lies in the fact that both cross-linguistically and within one language, not all NPIs can occur in exactly the same licensing environments. This is illustrated in the following contrast between any and yet (taken from Van der Wouden 1997: 141):

a. Chomsky didn't talk about any of these facts.

b. No one has talked about any of these facts.

c. At most three linguists have talked about any of these facts.

a. Chomsky didn't talk about these facts yet.

b. No one has talked about these facts yet.

c. *At most three linguists have talked about these facts yet.

Some NPIs, such as yet, seem to be choosier in the sense that they require a context that is negative in a stronger sense than (Strawson) downward entailing or nonveridical in order to be licensed. To capture this, Zwarts $(1996,1998)$ and Van der Wouden (1997) propose a hierarchy of negative contexts. In this hierarchy, which is defined in terms of entailments valid in the respective context, downward entailment constitutes the weakest form of negativity, and antimorphism, ${ }^{5}$ corresponding to classical negation, the strongest. Located in between are anti-additive contexts, induced by negative indefinites like nobody. ${ }^{6}$ Applying this classification, the particle yet is licensed in anti-additive environments, but not in contexts that are merely downward

\footnotetext{
${ }^{4}$ This is not a language-specific property of Greek, though. Many other languages exhibit NPIs that can be licensed in all kinds of non-veridical, but non-downward entailing contexts, such as Chinese (Lin 1996), Hindi (Lahiri 1998), Salish (Matthewson 1998), Navajo (Fernald and Perkin 2007) and Romanian (Falaus 2009).

${ }^{5}$ Formally, antimorphism is defined by the two clauses of de Morgan's law: a function $f$ is antimorphic iff for all $X, Y$ in the domain of $f$ it holds that $f(X \cup Y) \leftrightarrow f(X) \cap f(Y)$ and $f(X \cap Y) \leftrightarrow f(X) \cup f(Y)$.

${ }^{6}$ Formally, a function $f$ is anti-additive iff for all $X, Y$ in the domain of $f$ it holds that $f(X \cup Y) \leftrightarrow$ $f(X) \cap f(Y)$. 
entailing. ${ }^{7,8}$ NPIs like any that are allowed to occur in all kinds of downward entailing (or non-veridical) contexts are dubbed 'weak NPIs'; those that only appear in anti-additive contexts, 'strong NPIs'. Finally, a small group of elements may only occur in anti-morphic constructions, and for that reason are referred to as 'superstrong NPIs'?

Much current research on negative polarity, including much of the discussion in this issue as well, focuses on the question as to exactly which contexts license which NPIs and why (e.g., both Hoeksema's and Condoravdi's papers and their commentaries focus on these questions).

\subsection{NPIs and diachronic change}

Another domain of variation in the domain of polarity items and their licensing contexts concerns language change. NPIs are not always stable in the sense that their possible licensing contexts remain constant over time. Hoeksema shows in his paper that for instance Dutch enig used to be able to occur in all kinds of non-veridical contexts, whereas currently it is restricted to (a subset of) downward entailing contexts.

Apart from changes from one type of polarity to another, other developments have been reported where NPIs emerge from plain indefinites. Roberts and Roussou (2003) discuss the development of French negative indefinites, such as personne, which developed from a plain quantifier meaning 'a person' into an NPI meaning 'anybody'. ${ }^{10}$ This change, however, did not stop at this point and personne further developed into a negative indefinite.

Many of these changes in the development of German are described in Jäger's paper in this volume. She shows that in the history of German similar changes have taken place, but that, interestingly, changes in the reverse direction (from negative indefinite to NPI, from NPI to plain indefinite) are attested as well.

In sum, NPIs may occur in all kinds of contexts that are in some sense negative (non-veridical, downward entailing, anti-additive or anti-morphic) and NPIs may vary from one language to another, and also, synchronically and diachronically, within languages in terms of their exact licensing conditions. Most current research aims at capturing and explaining these differences. However, in order to do so, it becomes even more important to focus on a different question: why is it that certain lexical items may only occur in particular (negative) contexts in the first place?

\subsection{Explaining the NPI property}

Going beyond the issue of the proper characterization of the contexts in which NPIs are licensed, research has also addressed the question why NPIs are sensitive to these

\footnotetext{
${ }^{7}$ Since all downward entailing contexts are non-veridical, but not the other way round, non-veridicality can be seen as an additional, even weaker, layer in this hierarchy of negative contexts.

${ }^{8}$ Another notion, in terms of veridicality, is antiveridicality. A proposition $p$ is in an antiveridical context if the falsity of $p$ is entailed. Besides negation, negative indefinites and without induce antiveridicality.

${ }^{9}$ An example of the latter category would be the Dutch idiom voor de poes: zij is *(niet) voor de poes 'she's pretty tough', cf. Van der Wouden (1997).

${ }^{10}$ For a similar description of the rise and fall of Greek NPIs and negative indefinites, see Condoravdi and Kiparsky (2006).
} 
contexts. In other words, what property does an NPI have which renders it felicitous in exactly the contexts in which it is licensed?

One research tradition, dating back to Klima (1964) and advocated by Progovac (1992, 1993, 1994), Postal (2000), Szabolcsi (2004), Den Dikken (2002) and Herburger and Mauck (2007), takes NPI licensing to involve a syntactic relation between a proper (semi-)negative element and an NPI. Progovac, for instance, argues that NPI licensing shows significant similarities with syntactic binding and takes an unlicensed NPI to be on a par with an improperly bound anaphor. For Postal (2000) and Szabolcsi (2004), NPI any and its licenser are the joint spell-out of an underlying negative determiner [D NEG [SOME]]. According to Den Dikken (2002) and Herburger and Mauck (2007), finally, at least some NPIs require syntactic agreement with a negative head-in terms of minimalist feature checking.

The most dominant type of approach in the past twenty years, however, has sought a different type of explanation. It should be noted that under the syntactic approaches, in principle nothing determines which elements can be NPIs and which cannot. However, since NPIs are often indefinites or minimal expressions (e.g., lift a finger) the property common to many NPIs has been identified as their denoting low-scale elements. ${ }^{11}$ Hence, a major line of research has emerged aiming at explaining the NPI property from the semantics and pragmatics of low-scale elements.

Because NPIs denote elements located at the bottom of the scale, their occurrence in upward entailing contexts results in assertions that are not informative at all. In order to explain the fact that NPIs in upward entailing environments do not simply yield very weak assertions but are in fact ruled out, additional assumptions are needed. Kadmon and Landman (1993) propose that NPIs come with a strengthening requirement to the effect that the use of an NPI has to result in a stronger assertion. This strengthening requirement has, however, been criticized, as its status is unclear. Lahiri (1998) argues that NPIs associate with an operator meaning even (which is morphologically transparent in Hindi NPIs) whose presupposition renders the occurrence of low-scale elements in its scope infelicitous. In contrast, Krifka (1995) relates the unacceptability of NPIs in upward entailing contexts to scalar implicatures by requiring assertions to be as strong as possible. In order to explain that sentences with unlicensed NPIs are judged ungrammatical rather than pragmatically deviant, Chierchia (2006) builds the operator yielding scalar implicatures into the syntactic representation, effectively blurring the borderline between syntax, semantics and pragmatics.

Common to all accounts is the assumption that NPIs are banned from upward entailing environments because the fact that they denote low-scale elements is not compatible with these contexts. In downward entailing contexts, i.e., in contexts in which entailment relations are reversed, NPIs denote elements located at the upper end of the scale and, hence, lead to strong assertions. It is, thus, in downward entailing contexts where it makes sense to use an NPI.

One attractive trait of this perspective on NPIs is its potential to explain the fact that in many languages, NPI indefinites can also be used as so-called 'free choice

\footnotetext{
${ }^{11}$ For any it has been argued that it comes with an effect of widening the domain of quantification (Kadmon and Landman 1993). While for other indefinites, the domain of quantification is restricted to entities considered as relevant in the given context, any also quantifies over entities that would not usually be taken into account.
} 
items' (see Haspelmath 1997). The basic idea of unifying NPI and free choice uses of indefinites, which is currently investigated in a lot of research (a.o. Kratzer and Shimoyama 2002), is that alternatives associated with low-scale indefinites can also be exploited in a different way, which gives rise to an implicature of free choice.

However, the approaches discussed above have also been criticized. Apart from the fact that pragma-semantic infelicitousness generally does not render sentences ill-formed, they also only apply to NPIs that are indefinite/minimal in nature. They are challenged moreover by the fact that NPIs may also be licensed in non-downward entailing contexts and that not all NPIs seem to denote low-scale elements.

For instance, Giannakidou (1997, 1999, 2010a) argues that normally presupposition failures or semantic contradictions are not judged as being ungrammatical, as shown in (9), taken from Giannakidou (2010a):

a. The king of France is my brother.

b. John was born in NY, and he was not born in NY.

The judgments on unlicensed NPIs are much stronger: speakers generally sense them to be ungrammatical, which casts doubt on the idea that avoiding pragmatic infelicitousness is what is behind the licensing requirements of NPIs. This argument has been provided as well by Herburger and Mauck (2007), who instead propose that NPI licensing is actually an instance of syntactic feature checking. That unlicensed NPIs induce ungrammaticality is seriously problematic for Kadmon and Landman's, Krifka's and Lahiri's analyses, but less so for Chierchia's, as within his analysis the computation of such implicatures is taken care of in the syntax.

Giannakidou (1999, 2010a, 2010b) exploits another direction arguing that even within the domain of indefinite NPIs a distinction must be drawn between those NPIs that are scalar (which could potentially be analyzed as having their NPI property derived from their scalar properties) and those that are not. NPIs that can be licensed in non-veridical, non-downward entailing contexts are hypothesized to be 'non-deictic' and therefore non-scalar. Non-deictic elements are elements that cannot be assigned a contextual value by their assignment function, and should therefore be banned from veridical contexts. ${ }^{12}$ Note, however, that under Giannakidou's proposal the illformedness of unlicensed NPIs still ultimately reduces to some pragma-semantic requirements of NPIs that are violated, despite the assumption that these pragma-semantic requirements form lexical properties.

Again, it should be noted that one type of explanation does not exclude another one. For instance, Giannakidou's notion of non-deixis could very well account for the fact that certain elements are banned from veridical contexts, but may have less to say about those NPIs which may only occur in downward entailing contexts (where scale-reversal makes these NPIs licit again). Consequently, a careful investigation of what kinds of elements can occur in what kinds of (negative) contexts may thus not only provide more insight into what constitutes the exact licensing conditions, but also into which properties underlie such licensing conditions in the first place.

${ }^{12}$ See also Duffley and Larrivée (2010) for similar arguments in this direction. 


\section{Negative indefinites}

A class of expressions closely related to NPIs are negative indefinites. In English, a sentence containing an NPI indefinite and the licensing negation is (more or less) equivalent to one with a negative indefinite:
a. I didn't see anyone.
b. I saw no-one.

While negative indefinites in English seem to contribute negation themselves, in contrast to NPIs, the distinction between the two classes of indefinites is much less clear in other languages. In Polish for instance, negative indefinites are obligatorily accompanied by a negative marker, as in example (11) (taken from Błaszczak 2001), and thus seem to be much more like NPIs.

$$
\begin{aligned}
& \text { Ewa nie daje nikomu presentów. } \\
& \text { Ewa NEG gives n-body.DAT gifts.GEN } \\
& \text { 'Ewa doesn't give anyone a gift.' }
\end{aligned}
$$

[Polish]

But even in Polish, negative indefinites are in some contexts able to express negation by themselves. This is in particular the case when they are used as fragmentary answers, as in (12a). In contrast, NPIs such as English any, can never receive a negative interpretation in fragmentary answers.

$$
\begin{aligned}
& \text { a. Kto przyszedt? - Nikt. } \\
& \text { who came n-body } \\
& \text { 'Who came?' 'Nobody' } \\
& \text { b. Who came? - *Anybody. }
\end{aligned}
$$

The ability to contribute negation in fragmentary answers can, thus, be regarded as a defining property of negative indefinites, distinguishing them from NPIs (cf. Bernini and Ramat 1996 and Haspelmath 1997).

Due to the double-faced nature negative indefinites exhibit in many languagesin some contexts they contribute negation by themselves, in others they do notthe central question concerns their semantic status. In the following section, we will sketch the main approaches to this question.

\subsection{The status of negative indefinites}

To appreciate the challenges for a semantic analysis of negative indefinites, consider the following Italian examples:

a. Gianni non ha telefonato.

Gianni NEG has called

'Gianni didn't call.'

b. Nessuno ha telefonato.

n-body has called

'Nobody called.' 
In (13a) the semantic negation is introduced by the negative marker non. The sentence without non simply means 'Gianni called'. In (13b) nessuno acts like a negative quantifier, such as English nobody, and thus induces the semantic negation. However, if non and nessuno are combined in a clause, as in (14), only one semantic negation results, although from a compositional point of view two negations would be expected.

Gianni non ha telefonato a nessuno.

[Italian]

Gianni NEG has called to n-body

'Gianni didn't call anybody.'

The phenomenon where two (or more) negative elements that are each able to express negation in isolation yield only one semantic negation is called Negative Concord (NC) after Labov (1972), and has been discussed extensively in the literature. A large variety of languages exhibit NC (cf. Haspelmath 2005), where NC comes about in different forms. In some languages, a negative marker obligatorily accompanies all negative indefinites (or n-words as Laka (1990) refers to negative indefinites in NC languages), regardless of their number and position. This is the case in Czech, as the examples in (15) illustrate. Those languages are called Strict NC languages, following the terminology of Giannakidou (1997, 2000). In other languages, so-called Non-strict NC languages, NC can only be established between n-words in postverbal position and one element in preverbal position, either an $n$-word or a negative marker. This is shown in (16) for Italian. ${ }^{13}$

a. Milan*(ne-)vidi nikoho.

[Czech]

Milan NEG-saw n-body

'Milan doesn't see anybody.'

b. Dnes *(ne-)volá nikdo.

Today NEG-calls n-body

'Today nobody calls.'

c. Dnes nikdo *(ne-)volá.

Today n-body NEG-calls

'Today nobody calls.'

a. Gianni *(non) ha telefonato a nessuno.

Gianni NEG has called to n-body

'Gianni didn't call anybody.'

b. Ieri *(non) ha telefonato nessuno.

Yesterday NEG has called n-body

'Yesterday nobody called.'

c. Ieri nessuno (*non) ha telefonato (a nessuno).

Yesterday n-body NEG has called to n-body

'Yesterday nobody called (anybody).'

\footnotetext{
${ }^{13}$ It should be noted that this typology of NC languages is not exhaustive, and there are more fine-grained distinctions. In languages like Bavarian and West Flemish, for instance, NC is allowed to occur, but it is not obligatory (Den Besten 1989; Haegeman 1995). In French and Romanian, the combination of two $\mathrm{n}$-words gives rise to an ambiguity between an $\mathrm{NC}$ reading and a reading with two semantic negations (cf. De Swart and Sag 2002; Corblin et al. 2004; De Swart 2006, 2010; Falaus 2009).
} 
The central question surrounding NC concerns the apparent violation of semantic compositionality in examples like (14). How is it possible that two elements that each induce semantic negation together only yield one negation?

In the literature, two approaches have been dominant. The negative quantifier approach takes every n-word to be semantically negative and explains missing semantic negations as a result of some semantic absorption mechanism. According to these proposals (most notably Zanuttini 1991; Haegeman and Zanuttini 1991, 1996; and Haegeman 1995), NC is due to a process of negation absorption, analogous to Wh absorption as proposed by Higginbotham and May (1981). This idea has been formally spelled out by De Swart and Sag (2002), who argue that absorption corresponds to resumption of unary quantifiers in a polyadic quantifier framework (Van Benthem 1989; Keenan and Westerståhl 1997). Following this approach, every clause involving multiple negative elements thus receives both a resumptive and an iterative interpretation. The first corresponds to an NC reading, the second results in a double negation reading. This ambiguity is indeed attested for multiple negative constructions in French and Romanian. However, languages rarely exhibit this ambiguity between double negation and NC readings, and French and Romanian are typologically exceptional in this respect. Most languages assign to constructions involving multiple negative elements either an NC reading or a double negation reading - but not both. Thus for the resumption analysis to work correctly some additional mechanism must be assumed in order to account for the typological variation with respect to NC. Moreover, it should be noted that this proposal does not naturally extend to non-quantificational negative elements, such as negative markers.

The second major kind of approaches starts from the opposite assumption, i.e., that n-words are semantically non-negative. Several scholars have proposed that n-words are in fact special kinds of NPIs (Laka 1990; Ladusaw 1992; and Giannakidou 2000 being the most notable examples). If the lexical semantics of n-words such as Italian nessuno corresponds actually to anybody instead of nobody, the correct readings of examples like (14) follow immediately. It also follows that postverbal n-words require the presence of a negative marker in order to be licensed. Another argument in favour of analysing $n$-words as NPIs comes from the fact that n-words in a non-negative interpretation can also occur in certain environments that are not strictly negative. This is shown in the following Spanish example taken from Herburger (2001).

Dudo que vayan a encontrar nada.

[Spanish]

Doubt that go to find.SUBJ n-thing

'I doubt that they will find anything.'

This approach, however, faces an immediate problem. If n-words are semantically non-negative, how can the interpretation of sentences such as (13b), or fragmentary answers, where an n-word on its own induces semantic negation be derived? Laka (1990) explains this by assuming that the semantic negation can be expressed covertly by a phonetically null element. Giannakidou (2000) accounts for the semantic negation of fragmentary answers in terms of ellipsis of the negative marker. But this raises the question why n-words can be licensed by a covert negation, while this option is not available for genuine NPIs such as any. 
Because of the differences between NPI licensing and NC, Zeijlstra (2004, 2008) argues that $\mathrm{NC}$ is an instance of syntactic agreement, similar to other syntactic doubling phenomena such as subject-verb agreement or multiple gender marking (e.g., on adjectives and nouns). According to Zeijlstra, n-words are semantically non-negative elements carrying an uninterpretable negative feature [uNEG] that has to be checked by an interpretable negative feature [iNEG] on a semantic negation. Following Ura (1996) and Hiraiwa (2001, 2005), who argue that feature checking may also be instantiated between a single interpretable feature and multiple uninterpretable ones, Zeijlstra takes NC to be nothing but the realisation of syntactic agreement between a single negative operator and one or more elements carrying an uninterpretable negative feature ([uNEG]).

Thus, in example (14), the negative marker non is a negative operator that licenses the postverbal n-word nessuno:

$$
\text { Gianni non }_{[\mathrm{iNEG}]} \text { ha telefonato a nessuno }[\mathrm{uNEG}] \text {. }
$$

[Italian]

For cases where n-words are not overtly licensed by the negative marker, Zeijlstra argues that they are licensed by an abstract negative operator $\mathrm{Op}_{\neg}$. Addressing the question how the distribution of this $\mathrm{Op}_{\neg}$ is restricted to avoid overgeneration of negative readings, Zeijlstra claims that an abstract operator may be included in the syntactic representation of a clause only if its grammaticality cannot be accounted for without the abstract operator. In other words, in NC constructions without an overt negative operator, it must be the case that n-words are licensed by an abstract negative operator, since nothing else could have checked the features [uNEG] on the n-words. In all those sentences in which the sentence would be grammatical without the abstract operator, $\mathrm{Op}_{\neg}$ is banned from inclusion. To explain the contrast in the ability of n-words and NPIs to force the presence of a covert negation, Zeijlstra follows approaches to NPI licensing according to which unlicensed NPIs induce pragma-semantic infelicitousness, but not ungrammaticality in the strict sense. Hence, an abstract negative operator cannot rescue unlicensed NPIs.

To account for the difference between strict and non-strict NC languages, Zeijlstra argues that the negative marker may also be a non-negative agreement element. In strict NC languages, the negative marker carries an uninterpretable negative feature, whereas in non-strict NC languages, negative markers are semantically negative.

Penka (2010) extends the agreement approach to negative indefinites to languages not exhibiting NC. Motivation comes from the fact that even in those languages where negative indefinites seem to be negative quantifiers, the negation is not always interpreted in the position of the negative indefinite. A relevant example is the following German sentence, which under its most salient reading expresses a prohibition to eat any kind of pork.

$$
\begin{aligned}
& \text { Moslems dürfen kein Schweinefleisch essen. } \\
& \text { Muslims may n-DET pork eat } \\
& \text { 'Muslims are not allowed to eat pork.' }
\end{aligned}
$$

[German]

In this reading, negation takes wide scope over the possibility modal, whereas the indefinite meaning component is interpreted with narrow scope under the modal to receive a de dicto reading. This ability of negative indefinites to split their scope is a 
problem for the assumption that negative indefinites in non-NC languages are negative quantifiers (but see Geurts 1996 and De Swart 2000 for analyses). But it is readily explained if negative indefinites cross-linguistically are analysed as non-negative indefinites that have to stand in an agreement relation with sentential negation, which may itself be expressed covertly. The difference between $\mathrm{NC}$ and non-NC languages can then be attributed to a parameter fixing whether the semantic negation may be realized overtly or only covertly, and whether one interpretable negative feature can check multiple instances of uninterpretable features or a single one only.

\section{The papers in this issue}

Jäger distinguishes three main types of syntactic contexts (negative, non-negative affective and positive) and accordingly three types of indefinite pronouns and adverbs with respect to polarity (n-indefinites, NPI indefinites and 'normal' indefinites) characterized by two basic features (affective and negative). She also offers a typology of indefinite systems. The article's main focus is on diachronic changes of indefinites from one polarity type to another. A discussion of the development of indefinites in German provides important evidence for changes both towards 'more negative' and towards 'more positive'. Jäger presents a number of additional data from a wide range of languages supporting her conclusion that polarity type changes are not unidirectional. Drawing her results in with current accounts of language acquisition, she proposes that the observed changes are due to either lexical feature loss or introduction of a plus-valued feature.

In their commentary, Biberauer and Roberts highlight the importance of Jäger's proposal that diachronic development of NPIs towards 'more positive' interpretations is possible, alongside the more familiar developments towards 'more negative': as Jäger convincingly shows, polarity type changes may in fact occur in both directions. They compare Jäger's findings with the account of the development of French n-words put forward in Roberts and Roussou (2003), observing that, although this account is unidirectional, it also does not rely on the idea that indefinites or NPIs will naturally tend to become 'more negative'; rather, the account relies on the standard formal mechanisms of grammaticalization: loss of movement and, as with Jäger's proposals, loss of features. The development of these French n-words towards a more negative interpretation can therefore be viewed as a contingent one. One area in which Biberauer \& Roberts view Jäger's proposal as falling short, however, is in respect of the underspecified feature system she employs: they argue that this system is not fine-grained enough to capture the differences between the distributions of the types of indefinites found in familiar European languages, particularly, because her system cannot make a clear-cut distinction between the distribution of plain indefinites and Positive Polarity Items, such as some, which are banned from all kinds of affective contexts.

Hoeksema's article discusses the diachronic and synchronic distribution of the Dutch NPI enig ('any'). In combinations with singular count nouns, this indefinite determiner shows a shift from non-veridical environments in general to a strict subset thereof, namely negative, conditional and interrogative contexts. Hoeksema shows 
that at some point in its history enig has split into two uses, one of which is currently on its way out. Non-emphatic, non-referring enig is disappearing, whereas emphatic enig is stable within a set of environments similar to those licensing English any or ever. He concludes that in certain environments, such as strictly negative contexts, the possibility of being stressed changed enig from an expression primarily used to express non-referentiality, to an expression of emphasis, much like Greek stressed kanenas, and with an almost identical distribution (comparatives being the main difference). The main difference then with the Greek situation is that the two types of kanenas remained equally grammatical, whereas the non-referential, non-emphatic form of enig has virtually vanished.

Giannakidou's reply focuses on enig's meaning shift and shows that there is actually no shift from non-veridicality to downward entailment, but rather from weak to strong negative polarity. Giannakidou also emphasizes that this shift in distribution comes with a change in intonation and she argues that such stress effects do not only limit the distribution of Greek NPIs of the kanenas-series, as Hoeksema already discusses, but also applies to e.g., Japanese mo+ONE and Korean amwu-to NPIs, where focus markers are morphologically present on the NPIs. The path of enig to strict NPI-hood can then in a certain way be regarded as a result of grammaticalizing intonational properties as well. In comparing the older versus more modern usages of Dutch enig, Giannakidou builds further on the idea that two major sources for NPIhood known from the literature, scalarity and referential deficiency, may correlate with the weak versus strong NPI distinction. She suggests a correlation between the stricter NPI distribution of enig in Modern Dutch AND the emergence of an additional scalar dimension in its meaning.

The paper by Condoravdi focuses on the licensing of negative polarity items in one particular environment, namely in temporal clauses. While these contexts have often figured in specific analyses of NPI licensing (e.g., Linebarger 1987; Zwarts 1995; von Fintel 1999), Condoravdi offers the first systematic and comprehensive account. She shows that occurrences of NPIs in temporal clauses headed by before, after, since, and until can be reduced entirely to standard accounts of NPI licensing. Crucial is a notion of downward entailment factoring out presuppositions - von Fintel's (1999) Strawson downward entailment. By way of a detailed semantic analysis of temporal connectives, Condoravdi shows that the cases in which NPIs are licensed are all Strawson downward entailing. An important point in which Condoravdi's analysis diverges from previous accounts concerns the basic meaning of temporal connectives. She argues that the connectives simply denote temporal relations between times. The temporal property denoted by the temporal clause is coerced into a time by coercion operators like earliest and max. Assuming that in principle there is a choice of coercion operators, but only certain choices will result in the monotonicity properties NPIs require, she explains that often the occurrence of NPIs in temporal clauses forces certain readings.

In his comment, Krifka defends an alternative to Condoravdi's account of NPI licensing in temporal clauses that is in line with the more standard analysis in the style of Anscombe (1964) and does not make use of coercion operators. He proposes that many effects Condoravdi attributes to coercion operators can be derived by general pragmatic principles. As a consequence for the theory of NPI licensing, he argues 
that the more restricted notion of Strawson downward entailment does not need to be invoked for these cases. While downward entailment is sufficient to license NPIs, it is not necessary and only one way of fulfilling the more general licensing requirement of NPIs: they are restricted to contexts in which the use of an NPI better serves the communicative goals of the speaker than alternatives to the NPI.

The issue is concluded by a contribution by Soehn, Trawinski and Lichte, which is more like a manual and not accompanied by a commentary. It describes a procedure by which NPIs can be extracted semi-automatically from a corpus. This can serve as an important empirical basis for theoretical work on NPIs. Research on polarity items, as in other areas, tends to circle around the same examples and items. Moreover, research has focused on a small number of languages, besides English, mainly Dutch (Zwarts 1981; Van der Wouden 1997 among many others) and Greek (Giannakidou 1997, 1999). However, in order to arrive at valid cross-linguistic generalizations and theories, a broad database from a variety of languages is needed. The question which words and expressions show the behaviour typical for NPIs becomes particularly relevant for theories that try to relate their distribution to their meaning. We hope that the method outlined in this article will contribute to a broadening of the data taken into account for theoretical research, this way advancing our understanding of polarity phenomena.

Acknowledgements We would like to express our gratitude towards everyone who contributed to making this special issue possible. Starting with the Tübingen workshop on negation and polarity we would like to thank our co-organizers: Frank Richter, Jan-Philipp Soehn and Arnim von Stechow, as well as all our colleagues who volunteered to peer-review abstracts and the audience for inspiring and fruitful discussions. We are also indebted to the reviewers on whose expertise we could rely when making a selection of papers for this volume. Finally, we would like to thank Marcel den Dikken for his guidance, trust and enthusiasm in the preparation of this special issue.

Open Access This article is distributed under the terms of the Creative Commons Attribution Noncommercial License which permits any noncommercial use, distribution, and reproduction in any medium, provided the original author(s) and source are credited.

\section{References}

Anscombe, Gertrude. 1964. Before and after. The Philosophical Review 73: 3-24.

Bernini, Giuliano, and Paolo Ramat. 1996. Negative sentences in the languages of Europe: A typological approach. Berlin/New York: de Gruyter.

Błaszczak, Johanna. 2001. Investigation into the interaction between the indefinites and negation. Berlin: Akademie Verlag.

Chierchia, Gennaro. 2006. Broaden your views: Implicatures of domain widening and the "Logicality" of language. Linguistic Inquiry 37: 535-590.

Condoravdi, Cleo, and Paul Kiparsky. 2006. Tracking Jespersen's cycle. In Proceedings of the 2nd international conference of modern Greek dialects and linguistic theory, eds. Mark Janse, Brian Joseph, and Angela Ralli, 172-197. Mytilene: Doukas.

Corblin, Francis, Viviane Déprez, Henriette de Swart, and Lucia Tovena. 2004. Negative concord. In Handbook of French semantics, eds. Francis Corblin and Henriette de Swart, 417-455. Stanford: CSLI Publications.

De Swart, Henriette. 2000. Scope ambiguities with negative quantifiers. In Reference and anaphoric relations, eds. Klaus von Heusinger and Urs Egli, 109-132. Dordrecht: Kluwer Academic. 
De Swart, Henriette. 2006. Marking and interpretation of negation: A bi-directional OT approach. In Comparative and cross-linguistic research in syntax, semantics and computational linguistics, GURT 2004, eds. Rafaella Zanuttini, Hector Campos, Elena Herburger, and Paul Portner, 199-218. Washington: Georgetown University Press.

De Swart, Henriette. 2010. Expression and interpretation of negation. Dordrecht: Springer.

De Swart, Henriette, and Ivan Sag. 2002. Negative concord in Romance. Linguistics and Philosophy 25: 373-417.

Den Besten, Hans. 1989. Double negation and the genesis of Afrikaans. In Substrata versus universals in Creole genesis, eds. Pieter Muysken and Norval Smith, 185-230. Amsterdam: John Benjamins.

Den Dikken, Marcel. 2002. Direct and indirect polarity item licensing. Journal of Comparative Germanic Linguistics 5: 35-66.

Duffley, Patrick, and Pierre Larrivée. 2010. Anyone for non-scalarity? English Language \& Linguistics 14: $1-17$.

Falaus, Anamaria. 2009. Polarity items and dependent indefinites in Romanian. PhD Dissertation, University of Nantes, France.

Fauconnier, Gilles. 1975. Polarity and the scale principle. In Proceedings of the Chicago Linguistic Society, Vol. 11, 188-190. Chicago: Chicago Linguistic Society.

Fauconnier, Gilles. 1979. Implication reversal in a natural language. In Formal semantics and pragmatics for natural languages, eds. Franz Guenthner and S. J. Schmidt, 289-300. Dordrecht: Reidel.

Fernald, Ted, and Ellavina Perkin. 2007. Negative polarity items in Navajo. In Athabaskan languages conference papers, ed. Siri Tuttle, Vol. 7 of Alaska native language center working papers, 19-48.

Geurts, Bart. 1996. On No. Journal of Semantics 13: 67-86.

Giannakidou, Anastasia. 1997. The landscape of polarity items. PhD Dissertation, University of Groningen.

Giannakidou, Anastasia. 1999. Affective dependencies. Linguistics and Philosophy 22: 367-421.

Giannakidou, Anastasia. 2000. Negative. . .concord? Natural Language \& Linguistic Theory 18: 457-523.

Giannakidou, Anastasia. 2010a. Negative and positive polarity items: Licensing, compositionality and variation. In Semantics: An international handbook of natural language meaning, eds. Claudia Maienborn, Klaus von Heusinger, and Paul Portner. Berlin: Mouton de Gruyter (to appear).

Giannakidou, Anastasia. 2010b. The dynamics of change in Dutch enig: from nonveridicality to strong negative polarity. Natural Language \& Linguistic Theory 28: 4. doi:10.1007/s11049-010-91122-2.

Haegeman, Liliane. 1995. The syntax of negation. Cambridge: Cambridge University Press.

Haegeman, Liliane, and Rafaella Zanuttini. 1991. Negative heads and the neg criterion. The Linguistic Review 8: 233-251.

Haegeman, Liliane, and Rafaella Zanuttini. 1996. Negative concord in West Flemish. In Parameters and functional heads. Essays in comparative syntax, eds. Adriana Belletti and Luigi Rizzi, 117-179. Oxford: Oxford University Press.

Haspelmath, Martin. 1997. Indefinite pronouns. Oxford: Oxford University Press.

Haspelmath, Martin. 2005. Negative indefinite pronouns and predicate negation. In The world atlas of language structures, eds. Martin Haspelmath, Matthew S. Dryer, David Gil, and Bernard Comrie, 466-469. Oxford: Oxford University Press.

Herburger, Elena. 2001. The negative concord puzzle revisited. Natural Language Semantics 9: $289-333$.

Herburger, Elena, and Simon Mauck. 2007. A new look at Ladusaw's puzzle. In Proceedings of the workshop on negation and polarity, eds. Hedde Zeijlstra and Jan-Philipp Soehn. Tübingen: SFB 441.

Higginbotham, James, and Robert May. 1981. Questions, quantifiers and crossing. Linguistic Review 1: 41-79.

Hiraiwa, Ken. 2001. Multiple agreement and the defective intervention effect. In The proceedings of the MIT-Harvard joint conference (HUMIT 2000), eds. Ora Matushansky, Albert Costa, Martin-Gonzalez Javier, Lance Nathan, and Adam Szczegielniak, 67-80. Cambridge: MITWPL.

Hiraiwa, Ken. 2005. Dimensions in syntax. Manuscript, University of Tokyo.

Horn, Laurence. 1969. A presuppositional approach to only and even. In Proceedings of the Chicago Linguistic Society 5, eds. Robert I. Binnick, Alice Davison, Georgia M. Green, and Jerry. L. Morgan, 98-107

Horn, Laurence. 1989. A natural history of negation. Chicago: The University of Chicago Press.

Kadmon, Nirit, and Fred Landman. 1993. Any. Linguistics and Philosophy 16: 354-422.

Keenan, Edward, and Dag Westerståhl. 1997. Generalized quantifiers in linguistics and logic. In Handbook of logic and language, eds. Johan van Benthem and Alice ter Meulen, 837-893. Amsterdam: Elsevier. 
Klima, Edward. 1964. Negation in English. In The structure of language. Readings in the philosophy of language, eds. Jerry A. Fodor and Jerold J. Katz, 246-323. Englewood Cliffs: Prentice-Hall.

Kratzer, Angelika, and Junko Shimoyama. 2002. Indeterminate pronouns: The view from Japanese. In Proceedings of the third Tokyo conference on psycholinguistics, ed. Yukio Otso. Tokyo: Hituzi Syobo.

Krifka, Manfred. 1995. The semantics and pragmatics of polarity items. Linguistic Analysis 25: 209-258.

Labov, William. 1972. Sociolinguistic patterns. Philadelphia: University of Pennsylvania Press.

Ladusaw, William. 1980. Polarity sensitivity as inherent scope relations. New York: Garland Publishing.

Ladusaw, William. 1992. Expressing negation. In Proceedings of SALT II, eds. Chris Barker and David Dowty, 237-259. Cornell: Cornell Linguistic Circle.

Ladusaw, William. 1996. Negation and polarity items. In Handbook of contemporary semantic theory, ed. Shalom Lappin, 321-341. Malden: Blackwell.

Lahiri, Utpal. 1998. Focus and negative polarity in Hindi. Natural Language Semantics 6: 57-123.

Laka, Itziar. 1990. Negation in syntax: On the nature of functional categories and projections. PhD Dissertation, MIT.

Lin, Jo-Wang. 1996. Polarity licensing and wh-phrase quantification in Chinese. PhD Dissertation, University of Massachusetts, Amherst.

Linebarger, Marcia. 1987. Negative polarity and grammatical representation. Linguistics and Philosophy 10: 325-387.

Matthewson, Lisa. 1998. Determiner systems and quantificational strategies. Evidence from Salish. Worlds's theses 1. The Hague: Holland Academic Graphics.

Penka, Doris. 2010. Negative indefinites. Oxford: Oxford University Press.

Postal, Paul. 2000. An introduction to the grammar of squat. Manuscript, NYU.

Progovac, Ljiljana. 1992. Negative polarity: A semantico-syntactic approach. Lingua 86: 271-299.

Progovac, Ljiljana. 1993. Negative polarity: Downward entailment and binding. Linguistics and Philosophy 16: 149-180.

Progovac, Ljiljana. 1994. Negative and positive polarity: A binding approach. Cambridge: Cambridge University Press.

Roberts, Ian, and Anna Roussou. 2003. Syntactic change. A minimalist approach to grammaticalisation. Cambridge: Cambridge University Press.

Strawson, Peter F.. 1952. Introduction to logical theory. London: Methuen.

Szabolcsi, Anna. 2004. Positive polarity-Negative polarity. Natural Language \& Linguistic Theory 22: 409-452.

Ura, Hiroyuki. 1996. Multiple feature-checking: A theory of grammatical function splitting. PhD Dissertation, MIT.

Van Benthem, Johan. 1989. Polyadic quantifiers. Linguistics and Philosophy 12: 437-464.

Van der Wouden, Ton. 1997. Negative contexts. Collocation, polarity and multiple negation. London: Routledge.

von Fintel, Kai. 1999. NPI licensing, Strawson entailment, and context dependency. Journal of Semantics 16: 97-148.

Zanuttini, Rafaella. 1991. Syntactic properties of sentential negation. PhD Dissertation, University of Pennsylvania.

Zanuttini, Rafaella. 2001. Sentential negation. In The handbook of contemporary syntactic theory, eds. Mark Baltin and Chris Collins, 511-535. Malden: Blackwell.

Zeijlstra, Hedde. 2004. Sentential negation and negative concord. PhD Dissertation, University of Amsterdam.

Zeijlstra, Hedde. 2007. Negation in natural language: On the form and meaning of negative elements. Language and Linguistics Compass 1: 498-518.

Zeijlstra, Hedde. 2008. Negative concord is syntactic agreement. Manuscript, University of Amsterdam. http://ling.auf.net/lingBuzz/000645. Accessed October 2010.

Zeijlstra, Hedde. 2010. Negation and polarity. In The Cambridge handbook of generative syntax, ed. Marcel den Dikken. Cambridge: Cambridge University Press (to appear).

Zwarts, Frans. 1981. Negatief Polaire Uitdrukkingen I. GLOT 4: 35-132.

Zwarts, Frans. 1995. Nonveridical contexts. Linguistic Analysis 25: 286-312.

Zwarts, Frans. 1996. A hierarchy of negative expressions. In Negation: A notion in focus, ed. Heinrich Wansing, 169-194. Berlin: de Gruyter.

Zwarts, Frans. 1998. Three types of polarity. In Plurality and quantification, eds. Fritz Hamm and Erhard Hinrichs, 177-238. Dordrecht: Kluwer. 